\title{
Ensaio fotográfico de Antonio Saggese
}

Antonio Saggese (SP, 1950) é arquiteto pela FAU-USP, mestre e doutor em Filosofia (Estética) pela FFLCH-USP. Dedica-se à fotografia desde 1969, também como professor universitário. Participou de diversas coletivas dentro e fora do país e realizou exposições individuais no Masp, MIs-SP, Instituto Tomie Ohtake, Pinacoteca do Estado, Sesc Pompeia, MAM-RJ, Galeria Tempo, Galerias Diaframma e Ken Dammy em Milão. Participou do primeiro Arte-Cidade bem como da primeira seleção da Coleção Pirelli Masp. Foi contemplado com as bolsas Vitae (1992), Marc Ferrez (1986, 1996 e 2014), entre outras, e premiado pela I Quadrienal de Fotografia do MAM-sp e pela Associação Paulista de Críticos de Arte. Entre suas publicações estão Antonio Saggese - Fotoportátil (Cosac Naify, 2005) e Pittoresco (Edusp, no prelo).

Architect graduated from the University of São Paulo, master and doctor in Philosophy (Aesthetic), University of São Paulo. Dedicated to photography since 1969, also as a university professor. Participated in several group shows in Brazil and abroad, and has made individual exhibitions at Masp, MIS-SP, Instituto Tomie Ohtake, Pinacoteca do Estado, Sesc Pompeia, MAM-RJ, Galeria Tempo, Galerias Diaframma, and Ken Dammy in Milan. Among his publications are "Antonio Saggese - Fotoportátil" (Cosac Naify, 2005) and "Pittoresco" (Edusp, to be launched). www.saggese.art.br 


\section{O INGÊNUO E O MALDITO}

As fotos de Antonio Saggese parecem situar-se exatamente na fronteira entre o ingênuo e o maldito. Situação delicada, por certo, uma vez que expõe o ponto de contato entre esses dois polos, indicando o lugar ambivalente onde eles se separam e se integram. Seria essa uma possível tradução tropical do estado de espírito saturnino dos malditos europeus?

É bem provável que sim. Que o digam as imagens retiradas do conjunto intitulado "Mecânica do desejo", de 1988, no qual se percebe o olho do fotógrafo a vasculhar as paredes das emblemáticas borracharias nacionais. Esses flagrantes sempre deixam entrever um corpo feminino em meio a uma variedade de objetos cortantes - ou, dizendo melhor, pedaços de um corpo feminino repousando entre alicates, serrotes e congêneres que, combinados, descrevem uma estranha harmonia. Daí que, se tais fotos podem remeter aos singulares instrumentos de tortura da terrível imaginação de Sade, nada nelas evoca o sadismo: ao contrário, retirados de antigas "folhinhas", os recortes de jovens mulheres descansam na poeira, exalando bem mais a melancolia imposta pela passagem do tempo do que a violência erótica.

Tome-se ainda a inquietante Vênus tropical de corpo inteiro que, nua na edição original, aparece literalmente despelada e despedaçada na foto. Coberta de pó, ela se reduz a resíduos do que terá sido num passado inalcançável, fazendo lembrar os poemas eróticos de Kaváfis que, segundo Marguerite Yourcenar, por seu forte tom memorial parecem indicar, "num terreno que permaneceu seco, a altura até a qual as águas subiram outrora". Entulhadas de objetos e lembranças, as paredes fotografadas por Saggese expõem igualmente suas marcas d'água - mas uma água outra que, abismada no cotidiano escuro das borracharias brasileiras, terá talvez escoado mais rasa, porém não menos turva.

Traço fundamental dos malditos, a inflexão que envolve Eros se estende invariavelmente aos domínios de Tânatos. Não será diferente nesse conjunto, como se pode testemunhar na assombrosa imagem de um túmulo violado que exibe a mais singela das molduras. Foto da foto, a instaurar uma espécie de mise en abyme, também ela aciona a ambivalência entre o maldito e o ingênuo, pois ao mesmo tempo atenua e agrava o insondável fundo vazio que ocupa seu centro, tragando nosso olhar. Ambivalência que se torna ainda mais intensa em sua versão oposta, complementar e igualmente perturbadora: afinal, o que faz uma cândida chupeta azul-claro pousada bem no meio da notável pista imaginária onde se arriscam os mais altos e perigosos voos supersônicos?

Eliane Robert Moraes 


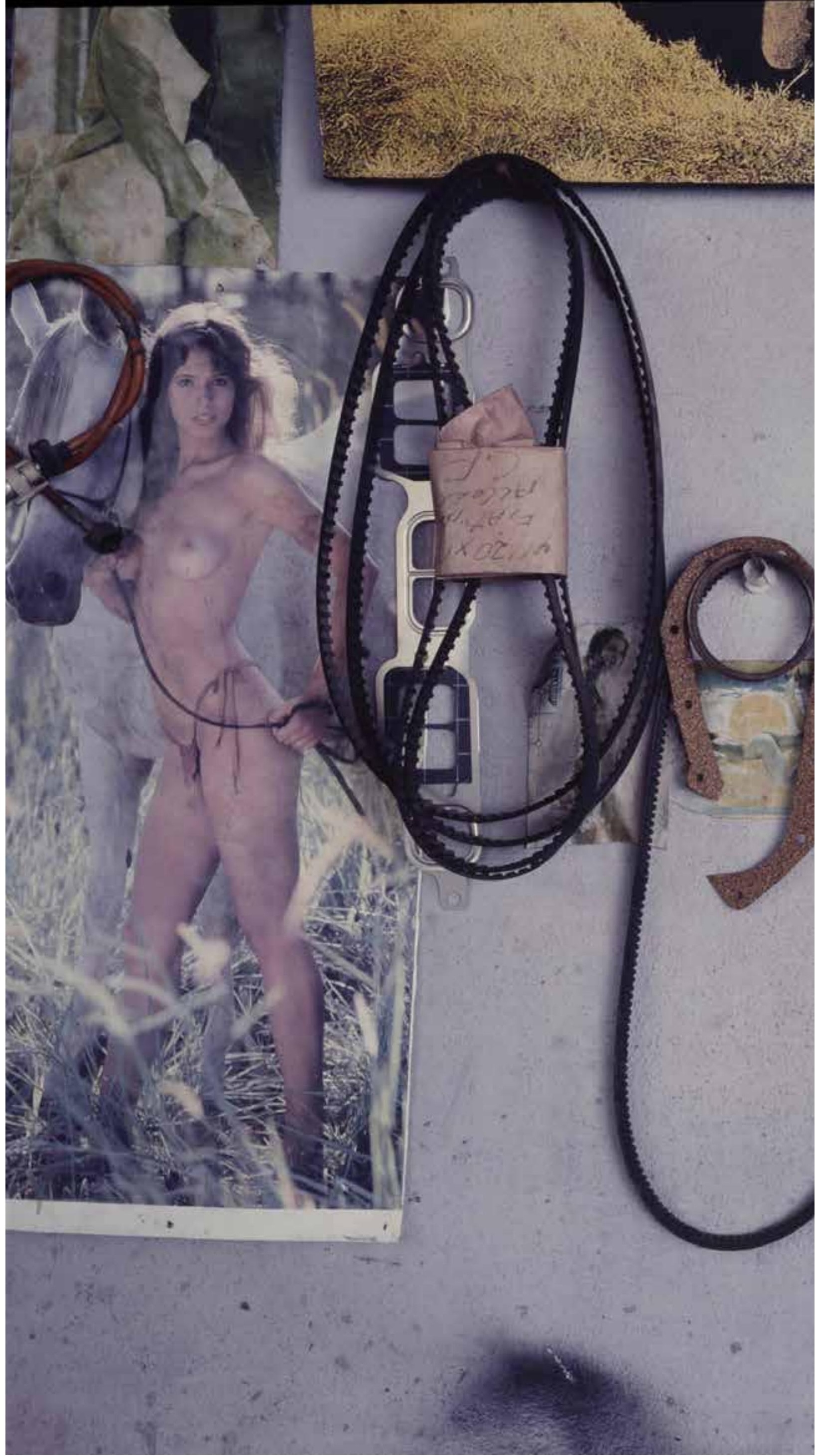



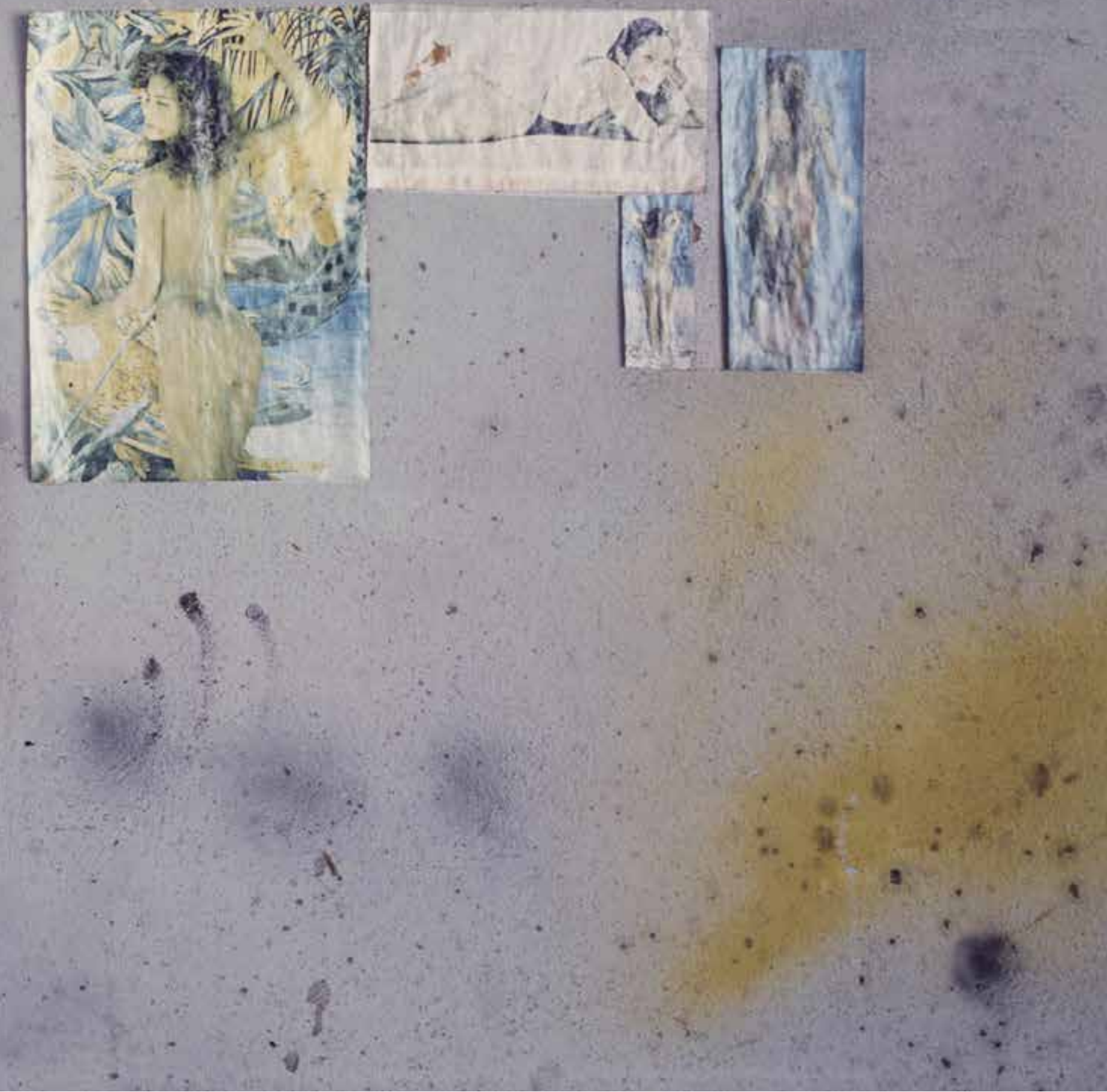


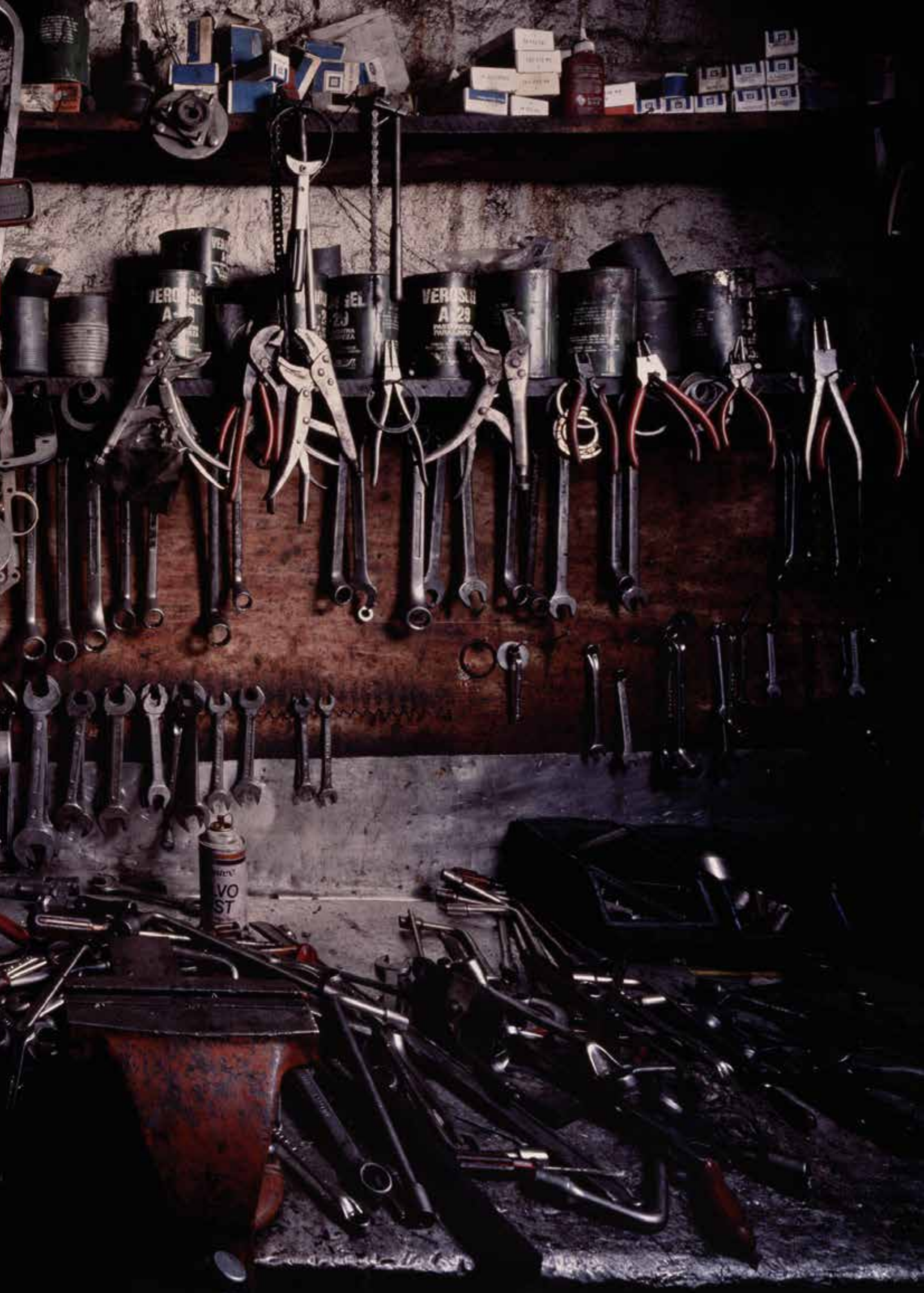




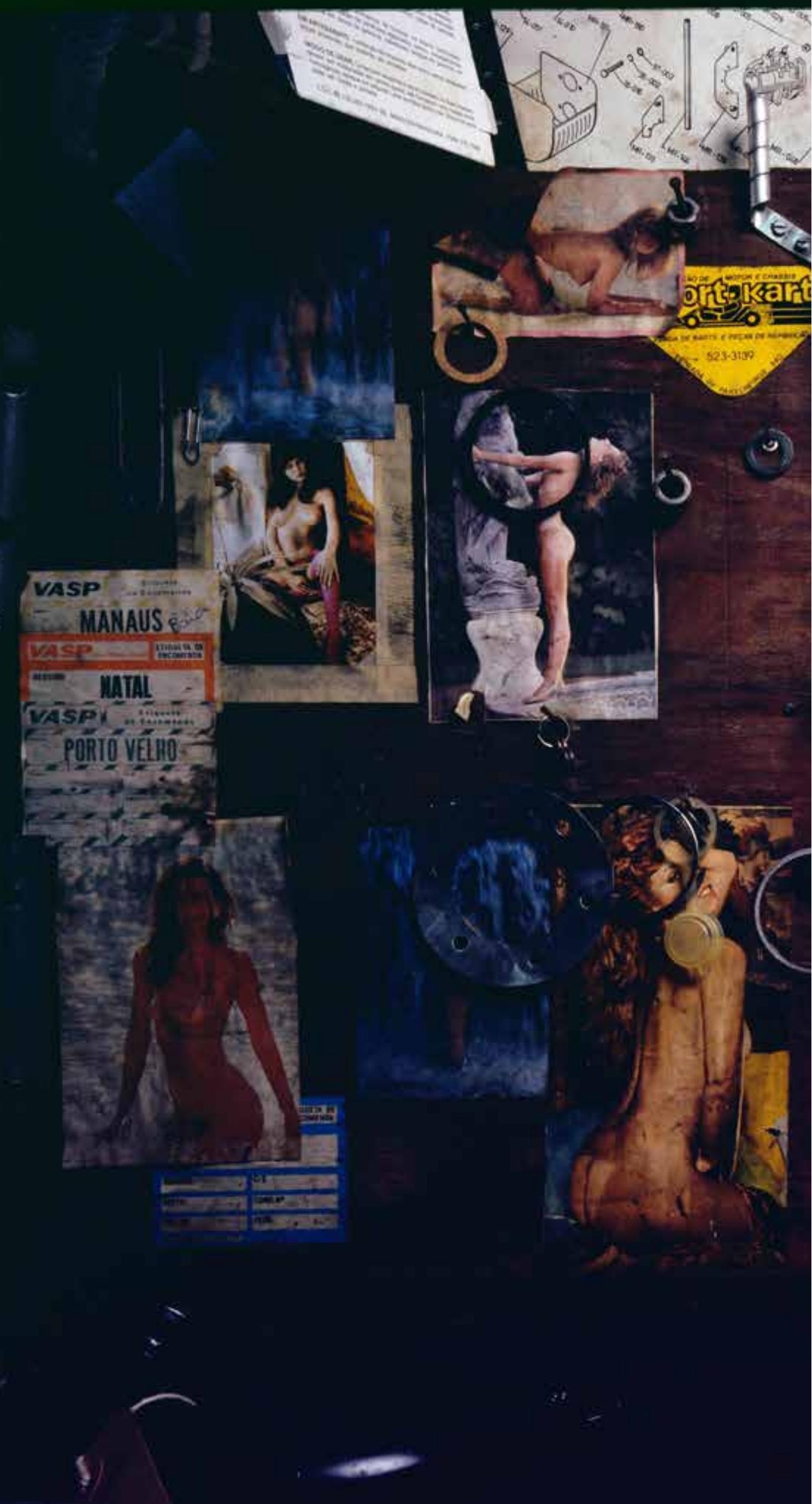




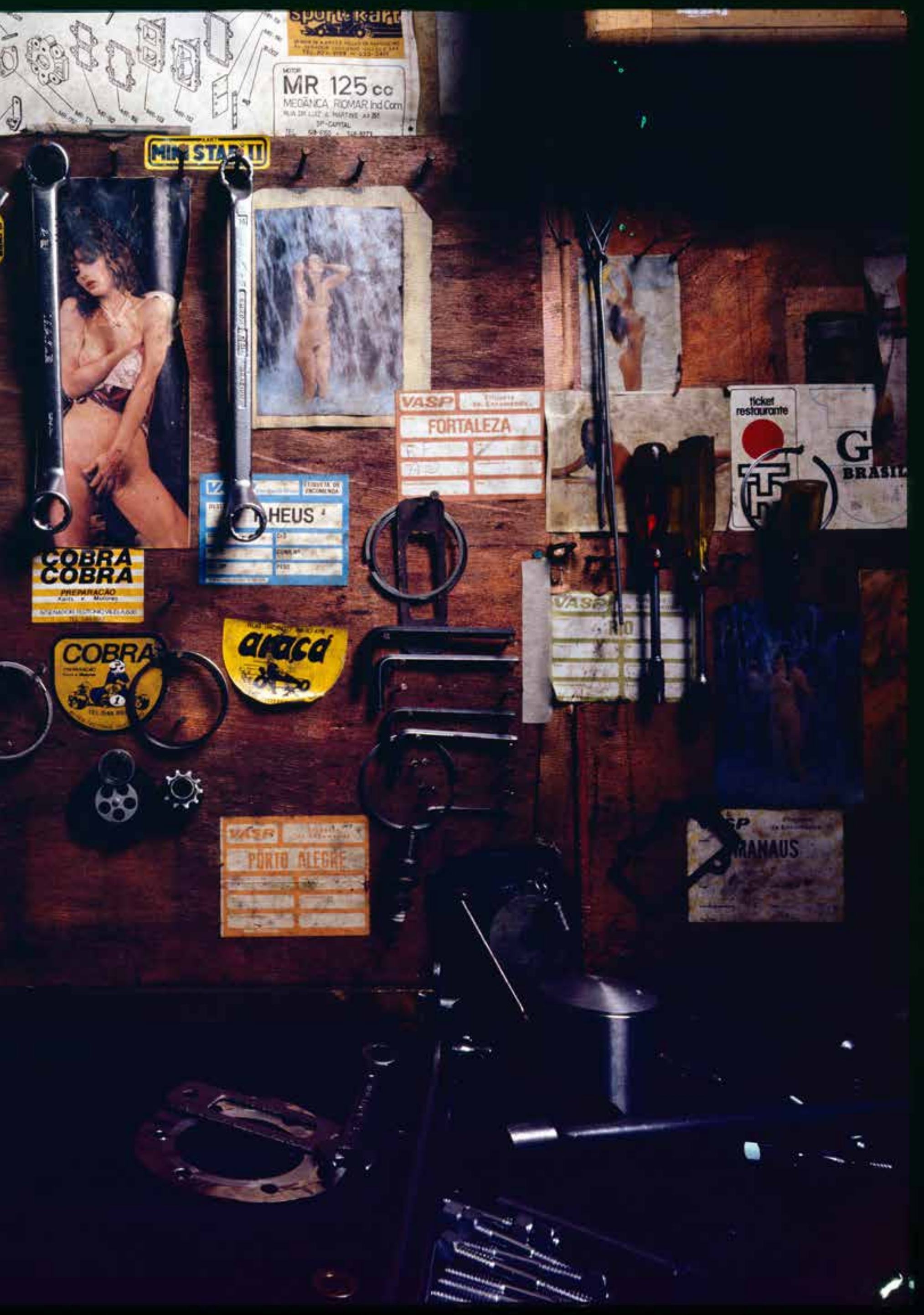




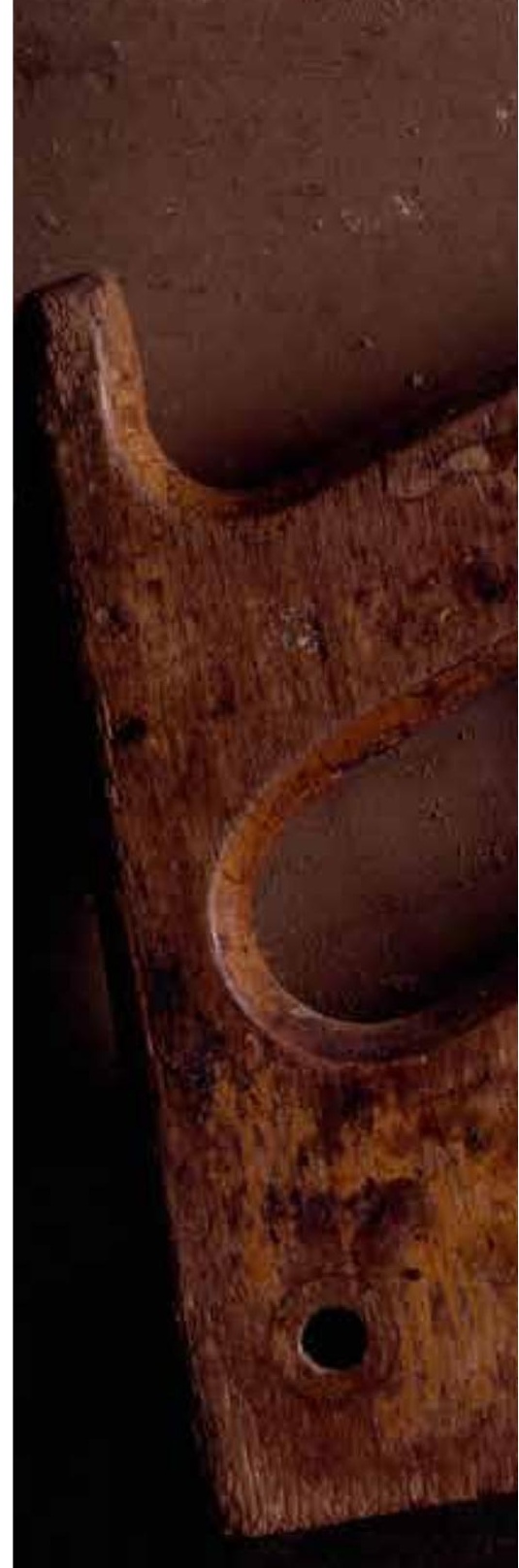




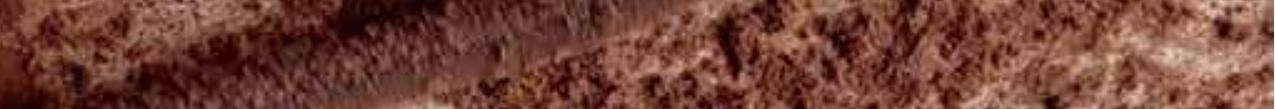

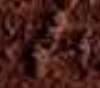

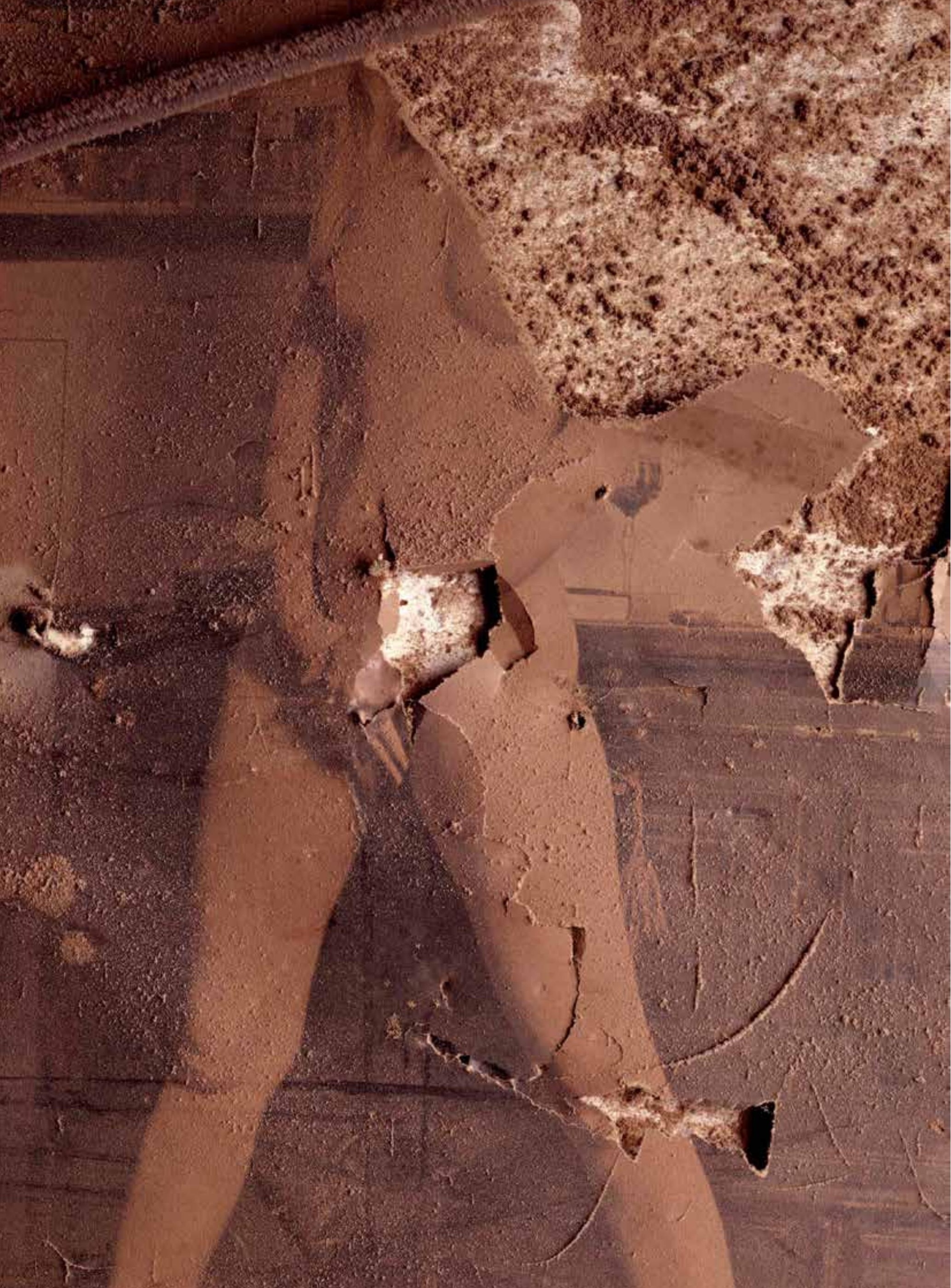




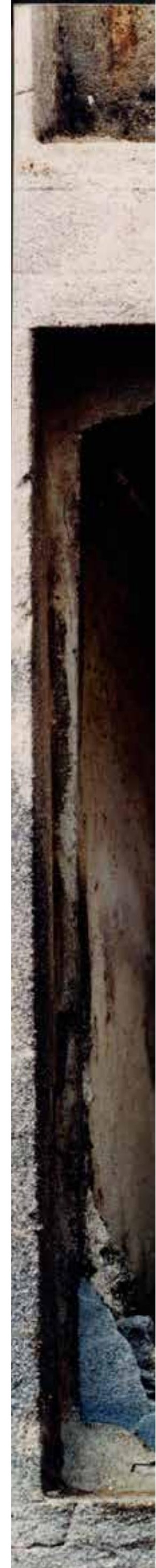




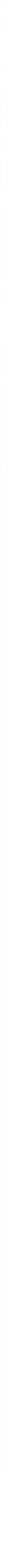


34 as horas

is:

imoce

Pasigye Semanal cos Desingoy

Chores

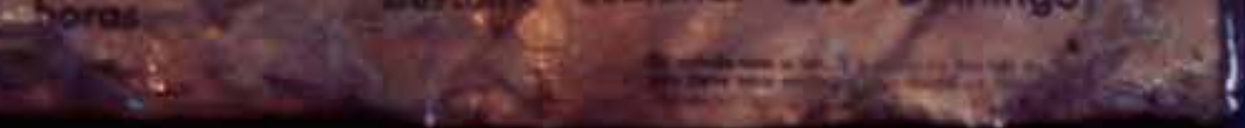
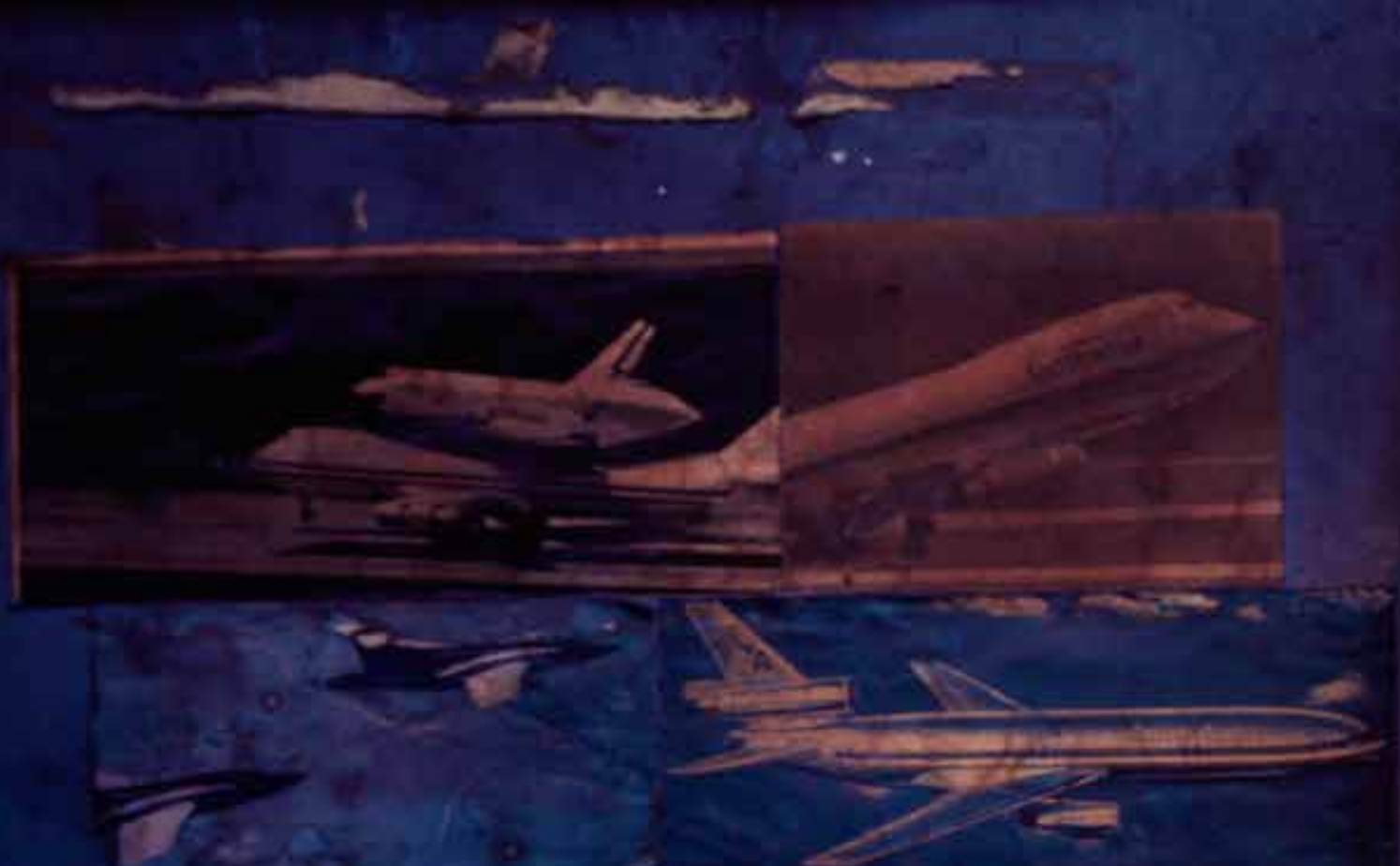

-

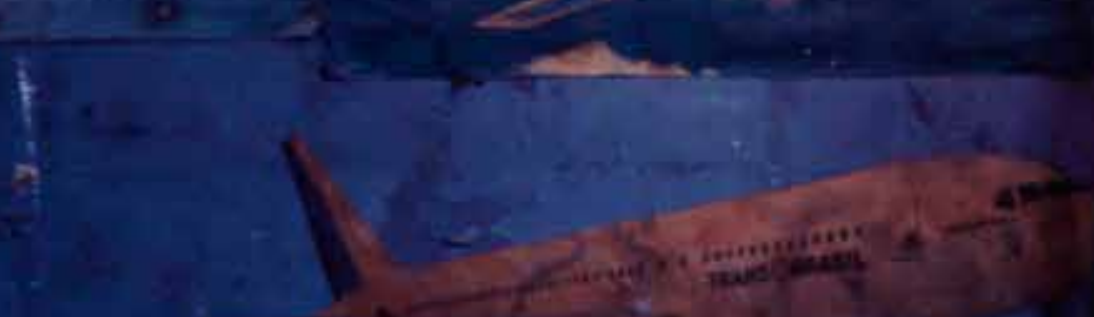

$+$

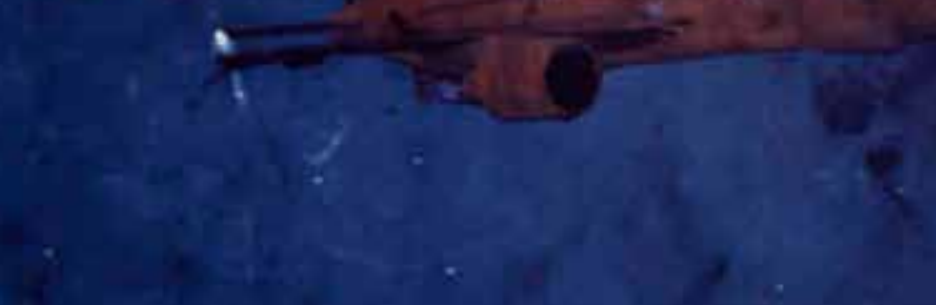

$+$ 


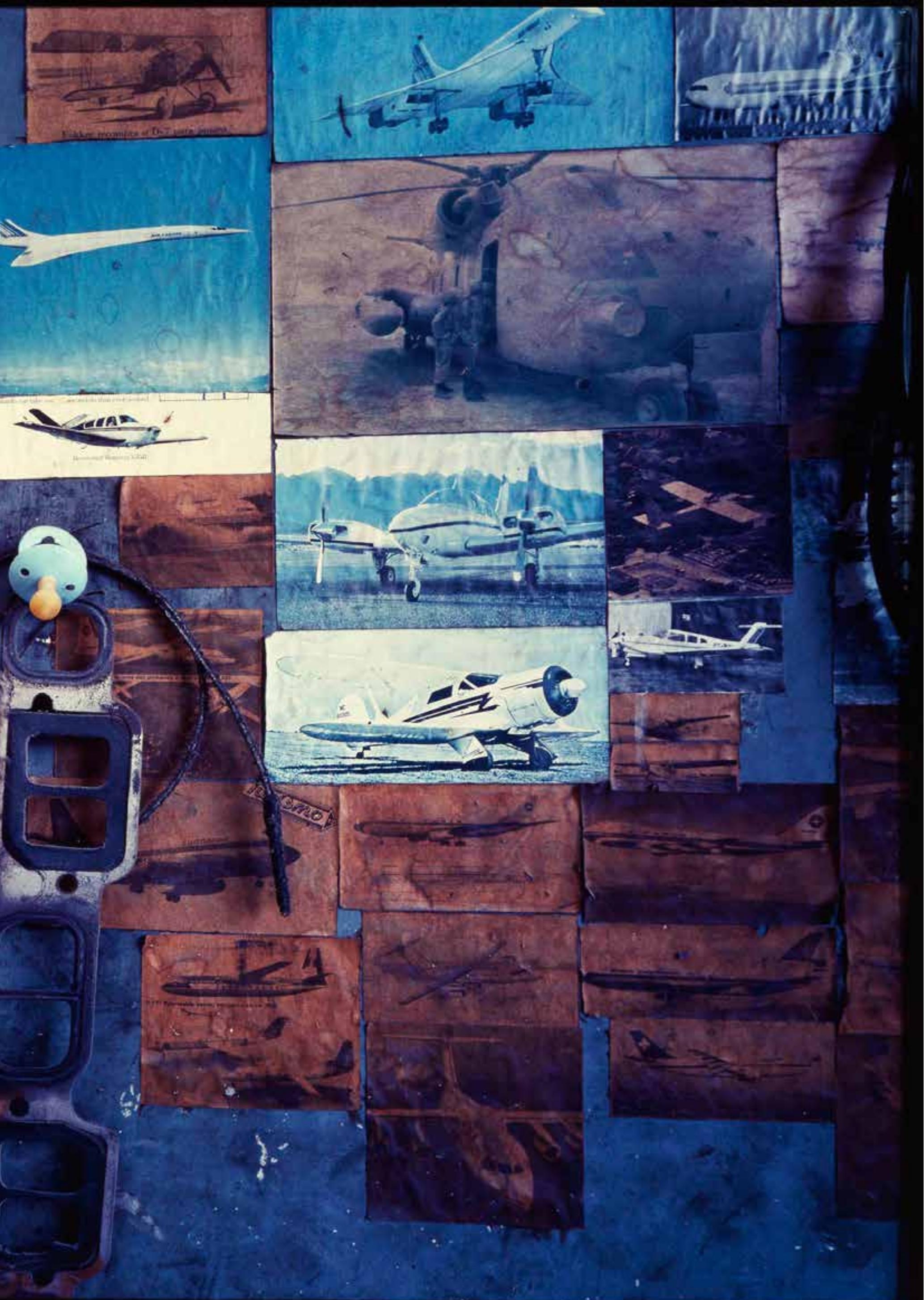

